\title{
Numerical Simulation of Plasma Jet Characteristics under Very Low-Pressure Plasma Spray Conditions
}

\author{
Tao Zhang ${ }^{1}$, Gilles Mariaux ${ }^{2}$, Armelle Vardelle ${ }^{2}$ and Chang-Jiu Li ${ }^{1, *}$ \\ 1 State Key Laboratory for Mechanical Behavior of Materials, School of Materials Science and Engineering, \\ Xi'an Jiaotong University, Xi'an 710049, China; tao.zhang0618@foxmail.com \\ 2 Institute for Research on Ceramics (IRCER), CNRS-University of Limoges, 87068 Limoges, France; \\ gilles.mariaux@unilim.fr (G.M.); armelle.vardelle@unilim.fr (A.V.) \\ * Correspondence: licj@mail.xjtu.edu.cn
}

Citation: Zhang, T.; Mariaux, G.; Vardelle, A.; Li, C.-J. Numerical

Simulation of Plasma Jet

Characteristics under Very Low-Pressure Plasma Spray Conditions. Coatings 2021, 11, 726. https://doi.org/10.3390/ coatings11060726

Academic Editor: Alenka Vesel

Received: 10 May 2021

Accepted: 13 June 2021

Published: 17 June 2021

Publisher's Note: MDPI stays neutral with regard to jurisdictional claims in published maps and institutional affiliations.

Copyright: (c) 2021 by the authors. Licensee MDPI, Basel, Switzerland. This article is an open access article distributed under the terms and conditions of the Creative Commons Attribution (CC BY) license (https:// creativecommons.org/licenses/by/ $4.0 /)$.

\begin{abstract}
Plasma spray-physical vapor deposition (PS-PVD) is an emerging technology for the deposition of uniform and large area coatings. As the characteristics of plasma jet are difficult to measure in the whole chamber, computational fluid dynamics (CFD) simulations could predict the plasma jet temperature, velocity and pressure fields. However, as PS-PVD is generally operated at pressures below $500 \mathrm{~Pa}$, a question rises about the validity of the CFD predictions that are based on the continuum assumption. This study dealt with CFD simulations for a PS-PVD system operated either with an argon-hydrogen plasma jet at low-power $(<50 \mathrm{~kW})$ or with an argon-helium plasma jet at high-power $(\geq 50 \mathrm{~kW})$. The effect of the net arc power and chamber pressure on the plasma jet characteristics and local gradient Knudsen number $(\mathrm{Kn})$ was systematically investigated. The Kn was found to be lower than 0.2 , except in the region corresponding to the first expansion shock wave. The peak value in this region decreased rapidly with an increase in the arc net power and the width of this region decreased with an increase in the deposition chamber pressure. Based on the results of the study, the local Knudsen number was introduced for detecting conditions where the continuum approach is valid under PS-PVD conditions for the first time and the CFD simulations could be reasonably used to determine a process parameter window under the conditions of this study.
\end{abstract}

Keywords: plasma spraying; very low-pressure; PS-PVD; CFD; shock wave; gradient-length local Knudsen number; continuum breakdown

\section{Introduction}

In the plasma spray-physical vapor deposition (PS-PVD) technique, a fine powder is injected into a high-temperature plasma jet produced by a D.C. non-transferred plasma torch. The powder particles are vaporized and then re-condensed onto a substrate [1-5]. Figure 1 shows the principle of the PS-PVD process. The coating is essentially formed from the vapor phase and may include clusters resulting from homogeneous nucleation in the gas phase [6]. This makes it possible to achieve coatings with various microstructures; e.g., dense, porous, columnar, which broadens the field of applications of coatings. For instance, yttria-stabilized zirconia (YSZ) coatings with a columnar structure could be used as barrier coatings while dense YSZ coatings could be used as oxygen ion-conducting layer in solid oxide fuel cells [7-10].

PS-PVD is typically operated under very low-pressure plasma spray conditions (50-200 Pa) and large range of electric power (up to $180 \mathrm{~kW}$ ). The characteristics of the plasma jet and mechanisms controlling the processing of the powder under such conditions are different from those encountered in conventional atmospheric plasma spray (APS), and also in low pressure plasma spray (LPPS) operated at 5-20 kPa [11-13], in which the coating is essentially formed from the piling up of melted particles impacting on the substrate. At very low pressures, the length and width of the plasma jet increase compared to the plasma jets operated at atmospheric pressure or low pressure. This is explained by the low 
collision rate between the various plasma species because of the low density of the gas. Also, the heating zone, specific enthalpy and velocity increase $[4,14]$ as well as the heating zone where the powdered material is processed.

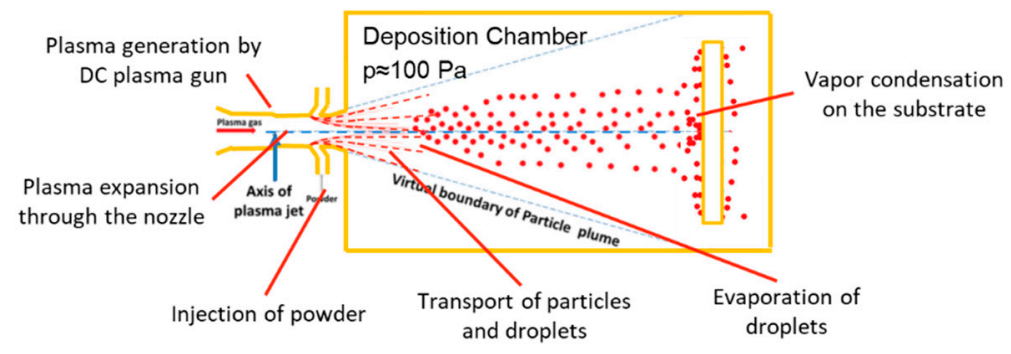

Figure 1. Principle of the PS-PVD process.

Different numerical studies investigated the effect of the plasma spray conditions on the powder processing and evaporation under PS-PVD conditions [15-17]. They have generally concluded that most of the heating and evaporation of the particles takes place between the powder injection point in the torch nozzle and nozzle exit [18]. In this zone, the pressure is close to the atmospheric pressure and, so, the plasma is much denser and plasma-particle transfers much more efficient. However, the flight distance of molten particles in the plasma jet issued from the torch $(>450 \mathrm{~mm})$ is much longer than that in the plasma torch nozzle (about $30 \mathrm{~mm}$ ), and the heating in the open plasma jet cannot be ignored [19]. Therefore, the characteristics of the whole plasma jet flow is necessary for the definition of operating process windows to achieve specific coating microstructures.

Computational fluid dynamics (CFD) is a powerful approach to simulate fluid flows and heat transfer in various geometries and systems, especially in engineering systems [20]; it solves the Navier-Stokes and energy equations based on the continuum assumption. CFD could be a useful tool to optimize the spray conditions under PS-PVD conditions. However, earlier research has shown that the continuum breakdown could occur in places within the plasma jet issuing in the deposition chamber under specific PS-PVD conditions and could affect the simulation accuracy [21]. A solution could be to combine the CFD with a Direct Simulation Monte Carlo (DSMC) method in the regions where the physics description provided by the CFD method is inadequate [22]. The numerical tools for both methods exist, although their combination and use are not straightforward. A solution could be a hybrid numerical technique that can commute from the CFD to DSMC technique when it is needed. It requires a suitable criteria of CFD failure [23]. The Knudsen number $(\mathrm{Kn})$ is generally used for evaluation of continuum transition; it is defined as the ratio of the gas molecule mean free path to a characteristic physical length scale of the system. Accordingly, fluid flows are divided into continuum flow $(\mathrm{Kn}<0.0001)$, slip flow $(0.0001<\mathrm{Kn}<0.1)$, transition flow $(0.1<\mathrm{Kn}<10)$ and free-molecule flow $(\mathrm{Kn}>10)$.

Under typical PS-PVD conditions the plasma jet can expand to more than $2 \mathrm{~m}$ in length and $200-400 \mathrm{~mm}$ in diameter [24].The characteristic physical length of the system is, thus, huge in comparison with the mean free path of plasma molecules, so the global Knudsen number may be small and yet the continuum approach may fail in some regions. Different breakdown parameters are proposed in the literature such as the simplified ChapmanEnskog parameter, Bird's parameter for expanding flows $[25,26]$ and the gradient-length local Knudsen number [27-29]. After Boyd, the latter parameter is a reliable criterion to detect continuum breakdown in flows. It uses a length scale determined by the gradient of a flow property $Q$ and is calculated as:

$$
\mathrm{Kn}=\frac{\lambda}{Q}\left|\frac{d Q}{d x}\right|
$$

where $\lambda$ is the molecular mean free path, $x$ the distance along the flow and $Q$ any flow property (temperature, density, velocity, etc.). 
In this study, numerical simulations of the plasma flow field under typical PS-PVD conditions were performed for both the regions within the plasma torch and deposition chamber using a CFD method. For two common plasma-forming gas compositions $\left(\mathrm{Ar}-\mathrm{H}_{2}\right.$ and $\mathrm{Ar}-\mathrm{He}$ ) and two electric power levels $(<50 \mathrm{~kW}$ and $\geq 50 \mathrm{~kW})$, the effect of two main spray parameters that are the plasma arc power and chamber pressure was investigated. The objective of this work was to determine if the CFD approach can yield acceptable predictions in the whole plasma domain under such operating conditions. Actually, a major drawback of DSMC is its computational cost that scales up when the Knudsen number decreases. The methodology involved the calculation of the plasma flow fields for various spray conditions and the calculation of the gradient-length local Knudsen Number.

\section{CFD Methods}

\subsection{Basic Assumptions of the Model and Governing Equations}

The main assumptions used in this study are as follows:

- The plasma and environmental gas in the deposition chamber were the same;

- The plasma properties depended on both temperature and pressure;

- The plasma jet was stationary, compressible and 2D axi-symmetrical. An axisymmetric model was used due to the azimuthal uniformity of the flows inside the expansion nozzle and downstream from it;

- The plasma was optically thin and in local thermodynamic equilibrium (LTE).

The governing equations of the CFD model involved the conservation equations of mass, momentum and energy (shown in Table 1), the turbulence equations and a real-gas law with pressure- and temperature-dependent properties. The turbulence was modeled by the shear-stress transport (SST) $\mathrm{k}-\mathrm{\omega}$ model. This model was selected as it has the ability to handle compressibility flow effects, large gradients and laminar/turbulent transition of compressible flows [30,31]. Ghalandari [20] also showed that, under conventional plasma spray conditions, the predicted plasma temperature and velocity agreed better with experimental data than those predicted with the classical $k-\varepsilon$ and $k-\omega$ models.

Table 1. Governing equations of the thermal plasma model.

\begin{tabular}{cc}
\hline Variable & Equation \\
\hline Mass & $\frac{\partial \rho}{\partial t}+\nabla \cdot(\rho \vec{v})=0$ \\
Momentum & $\frac{\partial}{\partial t}(\rho \vec{v})+\nabla \cdot(\rho \vec{v} \vec{v})=-\nabla p+\nabla \cdot(\overline{\bar{\tau}})+\rho \vec{g}$ \\
Energy & $\frac{\partial}{\partial t}(\rho E)+\nabla \cdot(\vec{v}(\rho E+p))=\nabla \cdot\left(k_{\text {eff }} \nabla T-\sum_{\mathrm{j}} h_{\mathrm{j}} \vec{J}_{\mathrm{j}}+\left(\overline{\bar{\tau}}_{\mathrm{eff}} \cdot \vec{v}\right)\right)$ \\
\hline
\end{tabular}

In these equations $t$ is the time, $\rho$ and $k_{\text {eff }}$ the density and effective thermal conductivity of the gas mixture, respectively, $\vec{v}$ the velocity vector, $p$ the pressure, $\vec{g}$ the gravity acceleration, $\overline{\bar{\tau}}$ the stress tensor, $T$ the temperature, $E$ the specific energy of the flow, $h_{\mathrm{j}}$ the specific enthalpy of the gas mixture component $j, \overline{\bar{\tau}}_{\text {eff }}$ is the effective stress tensor and $\vec{J}_{\text {eff }}$ is the diffusion flux of the gas mixture component $j$.

The set of discretized Reynolds-averaged Navier-Stokes (RANS) equations was solved with the CFD code Fluent.17 (ANSYS, Inc, Canonsburg, Pennsylvania, USA) with the density-based solver for high-speed compressible flows, implicit numerical scheme, and time-derivative preconditioning algorithm (advection upstream splitting method or AUSM) because of the numerical rigidity of the solved equations. The time-derivative preconditioning algorithm modifies the time-derivative term in the conservation equations, allowing the acoustic speed to be rescaled, thus reducing the stiffness of the system to be solved [21]; it is suitable only for pseudo-transient simulations where the goal is to achieve a steady solution [17]. Further details of the model can be found in previous articles [17,21] and the ANSYS Fluent Theory Guide (ANSYS Academic, 2016). 


\subsection{Operating Conditions of the PS-PVD System and Gas Thermodynamic and Transport Properties}

In this study, two sets of spray conditions commonly used for commercial low-power $(<50 \mathrm{~kW})$ and high-power plasma torches $(>50 \mathrm{KW})$ were investigated. They are given in Table 2. The first set used a mixture of argon and hydrogen gases (16\% vol.) and the second a mixture of argon and helium gases (34\% vol.). In plasma spraying, hydrogen and helium are generally added to the argon plasma-forming gas so as to increase the enthalpy and thermal conductivity of the gas mixture and, improve the processing of the particles injected in the plasma jet.

Table 2. Operating parameters for the $\mathrm{Ar}-\mathrm{H}_{2}$ and $\mathrm{Ar}-\mathrm{He}$ plasma jet.

\begin{tabular}{lcc}
\hline \multicolumn{1}{c}{ Spray Parameter } & Low-Power Plasma Torch & High-Power Plasma Torch \\
\hline Net electric power input to & $22.5-40$ & $50-70$ \\
the gas, $\mathrm{kW}$ & $40 \mathrm{Ar} / 8 \mathrm{H}_{2}$ & $60 \mathrm{Ar} / 30 \mathrm{He}$ \\
Plasma gas flow rate, slpm & 6 & 12.5 \\
Torch Nozzle diameter, $\mathrm{mm}$ & $100-500$ & $100-500$ \\
Chamber pressure, Pa & $\sim 0.4$ & $\sim 1$ \\
Spray distance, $\mathrm{m}$ & &
\end{tabular}

The temperature- and pressure-dependent properties of both gas mixtures were calculated and/or drawn from the work of Murphy [32-34] and NASA Chemical Equilibrium with Applications (CEA2) software [35].

Figure 2 shows the variation of the specific heat of both gas mixtures with the temperature at different pressures $(100,1000$ and 100,000 Pa). It highlights the non-linearity of the specific heat $\left(C_{p}\right)$ with temperature and its dependence on the dissociation and ionization phenomena that increase the energy storage capacity of the plasma and, thus, its enthalpy.

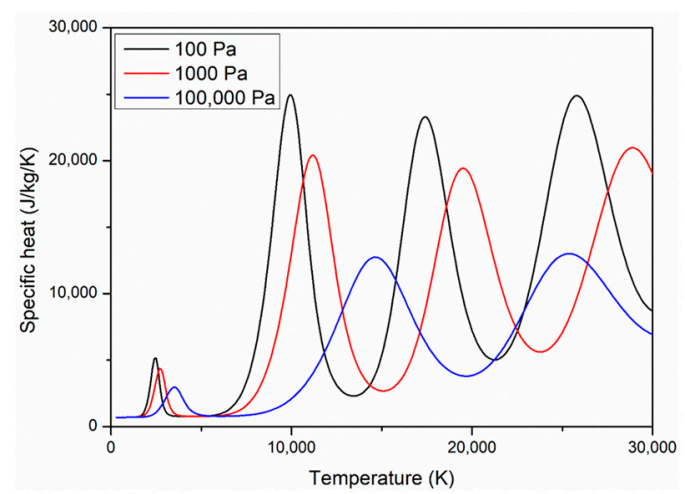

(a)

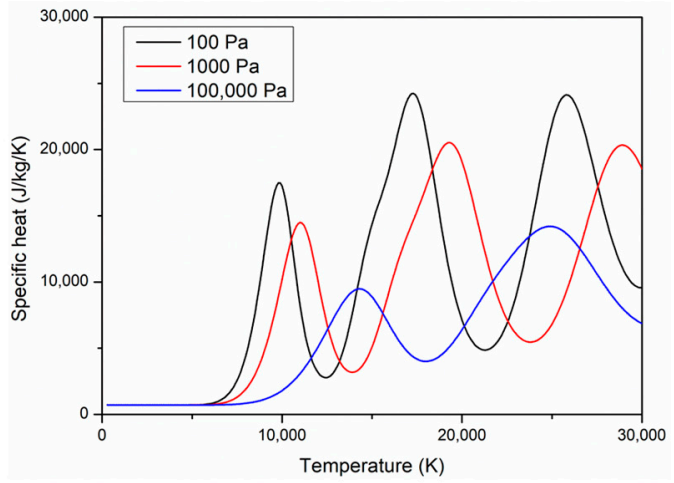

(b)

Figure 2. Variation of gas specific heat with temperature at different pressures: (a) Ar- $17 \%$ vol. $\mathrm{H}_{2}$, and (b) Ar- $34 \%$ vol. $\mathrm{He}$.

In Figure 2a, the first peak corresponds to the dissociation of $\mathrm{H}_{2}$ while the next peaks correspond to the ionization of hydrogen and first ionization of argon. When the pressure decreases, the dissociation and ionization temperature decrease and the $C_{p}$ peaks are shifted to lower temperatures and their maximum values increase. As the first ionization energy of helium $(24.59 \mathrm{eV})$ is higher than that of argon $(15.76 \mathrm{eV})$, the first peak in the argon-helium mixture (Figure $2 \mathrm{~b}$ ) corresponds to the first ionization of argon and is less intense than in the argon-hydrogen mixture.

\subsection{Computational Domain and Boundary Conditions}

The 2D axi-symmetric computational geometry domains (Figure 3) used for the numerical simulation included a part of the plasma torch and the chamber. The torch region represents the nozzle-anode of the low-power (F4 torch from Oerlikon Metco, Pfaeffikon, 
Schwyz, Switzerland) and high-power (O3CP torch from Oerlikon Metco) plasma spray torches with convergent-divergent nozzles used to adapt the flow to very low-pressure conditions. In the chamber, the computational domain was limited to a conical frustum that is supposed to correspond to the low-pressure expansion of the plasma jet issuing in the chamber. The structured mesh was iteratively refined in the plasma torch, boundary layer and high gradient regions until the solution became grid independent. The total number of cells were 29,522 (about 3000 in the plasma torch and 26,522 in the chamber) and 143,457 (about 9000 in the plasma torch and 134,457 in the chamber) for the F4 and O3PC plasma torch, respectively.

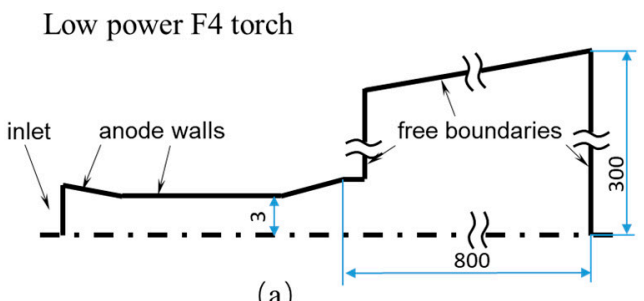

(a)

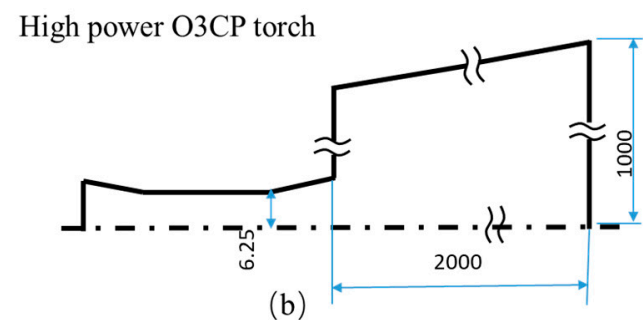

(b)

Figure 3. Computational domains: (a) low-power (F4), and (b) high-power plasma torch (O3CP). All the dimensions are expressed in $\mathrm{mm}$.

The plasma generation in the plasma torch is due to the conversion from electrical to thermal energy in the plasma-forming gas. The temperature imposed at the plasma torch domain inlet corresponded to the average temperature of the gas derived from the average specific enthalpy $(h(T))$ of the plasma gas calculated from the following energy balance [36]:

$$
\mathrm{P}_{\text {elec }}=V \times I=h(T) / \bar{m}
$$

where $V$ and $I$ are the arc voltage and arc current, respectively and $\bar{m}$ the gas mass flow rate. The temperature of the nozzle wall was set so as to cool down the flow according to the actual torch efficiency defined as the ratio of the electric power input to the plasma torch minus the heat losses to the torch cooling water, to the input electric power [21]. No slip boundary condition was applied at the walls and The pressure and temperature were imposed at the domain open boundaries $[17,21]$. Table 3 shows the main boundary conditions for the fluid equations.

Table 3. Boundary conditions used in the CFD model.

\begin{tabular}{cccccc}
\hline $\begin{array}{c}\text { Torch Net } \\
\text { Power, kW }\end{array}$ & Boundary Type & Torch Type & $\begin{array}{c}\text { Temperature, } \\
\text { K }\end{array}$ & Pressure, Pa & Mass Flow Rate, kg/s \\
\hline $22.5,30,40$ & Inlet & F4 & $14,200,14,950,16,550$ & - & 0.0012 \\
$50,60,70$ & O3CP & $15,100,16,300,18,500$ & 0.00187 \\
- & Torch anode & F4 & 1473 & - \\
& wall & O3CP & 1000 & - \\
- & Free boundaries & F4 & 873 & $100,200,500$ & - \\
\hline
\end{tabular}

\subsection{Continuum Breakdown Parameter}

The breakdown parameter used in this study was the Gradient-Length Local Knudsen Number Kn [27] given in Equation (1). The calculation of Kn requires the calculation of (i) the molecular mean free path $\lambda$ and (ii) the local gradient of gas density, temperature or velocity. The mean free path can be calculated from the kinetic theory of gases as:

$$
\lambda=\frac{k_{\mathrm{B}} T}{\sqrt{2} \pi d^{2} P}
$$


where $k_{B}$ is the Boltzmann constant, $T$ the temperature, $P$ the pressure, and $d$ the diameter of the gas molecules.

However, as the diameter of gas mixture particles is difficult to determine, the mean free path was calculated as $[37,38]$ :

$$
\lambda=(16 \mu / 5)(2 \pi R T)^{-1 / 2} / \rho
$$

where $\mu$ is the dynamic viscosity, $T$ the temperature, $R$ the gas constant, and $\rho$ the gas density.

The breakdown parameter Kn was calculated as the maximum of $\frac{\lambda}{T}\left|\frac{d T}{x}\right|, \frac{\lambda}{V}\left|\frac{d V}{x}\right|$ and $\frac{\lambda}{\rho}\left|\frac{d \rho}{x}\right|$ as suggested by Wang and Boyd [28] to take into account the heat and viscosity sources of continuum breakdown, where $\rho$ is the density, $T$ the temperature and $V$ the velocity. Wang suggested that the breakdown occurred when Kn was higher than 0.05 [29].

\section{Results and Discussion}

\subsection{Characteristic Features of Plasma Jets at $100 \mathrm{~Pa}$}

\subsubsection{Ar-H2 Plasma Jet}

At the torch exit, the pressure (about $15 \mathrm{kPa}$ ) is much higher than the chamber pressure and the plasma jet is highly under-expanded, which leads to an additional expansion of the plasma gas flow. The characteristics of such a jet issuing from a round nozzle are shown in Figure 4 [39].

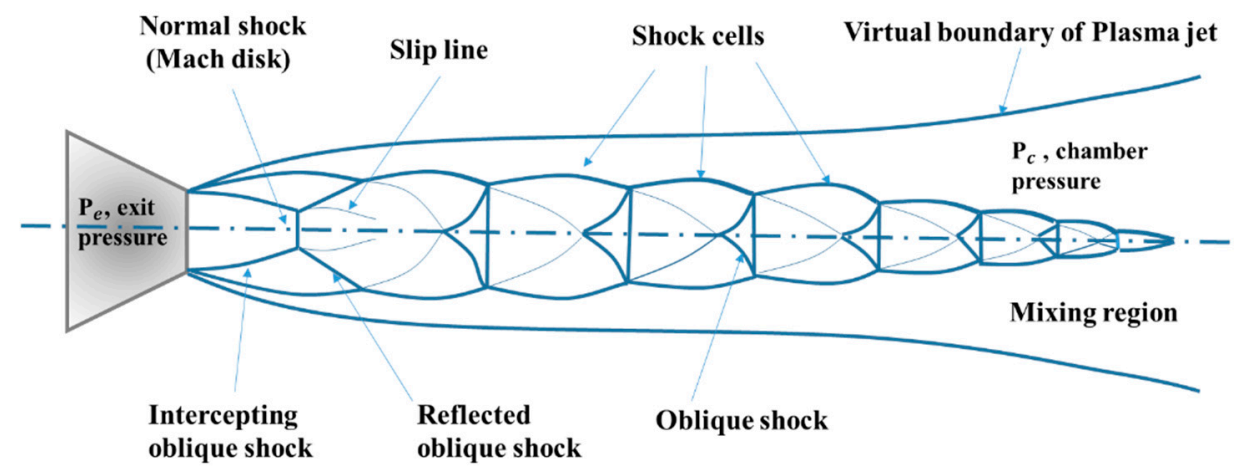

Figure 4. Schematic of the highly under-expanded jet adapted from [39].

Figure 5a-c show the predicted temperature, velocity and pressure fields of the $\mathrm{Ar}-\mathrm{H}_{2}$ plasma jet when the low-power plasma torch is operated at $22.5 \mathrm{~kW}$ and $100 \mathrm{~Pa}$. Under the conditions of the study, the plasma jet presents the typical characteristics of a supersonic fluid flow and exhibits large fluctuations in temperature, velocity and pressure after the plasma jet comes out of the torch nozzle and expands in the low-pressure chamber. Up to $0.7 \mathrm{~m}$ from the nozzle exit, its behavior is mainly dominated by compressible effects. The plasma jet undergoes an isentropic expansion, up to recompression through shock waves; its static pressure tends to equilibrate with the ambient pressure by means of expansion and compression zones, where the pressure oscillates around the chamber pressure. The temperature and velocity of the jet abruptly vary when the gas goes through a shock. The locations of the maximum values of temperature coincide with those of minimum values of velocity along the plasma jet axis and vice versa. The high temperature peaks (up to $14,500 \mathrm{~K})$ correspond to the luminous diamond-like structure regions observed in PS-PVD experiments $[11,40]$. 

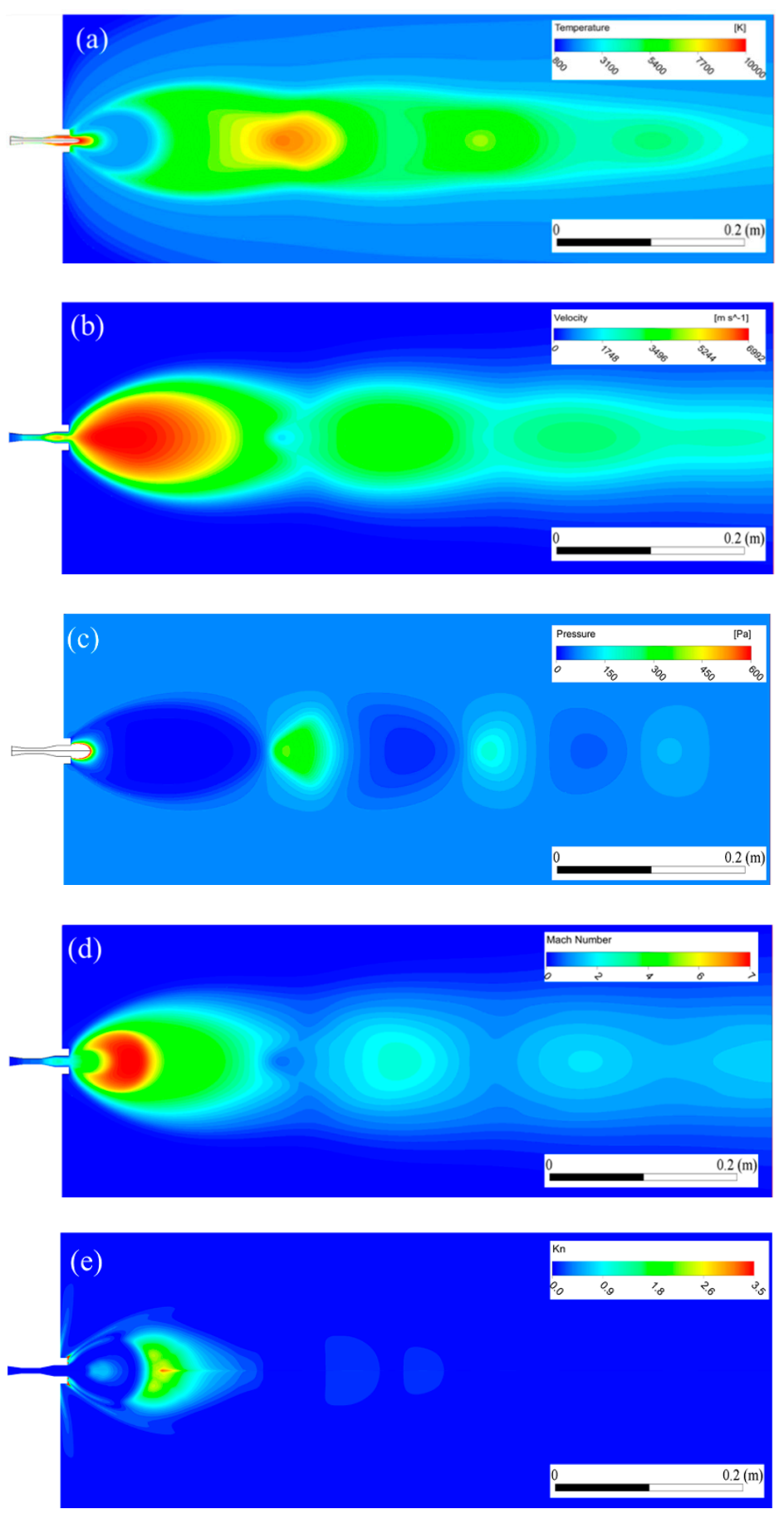

Figure 5. 40Ar-8H2 plasma jet fields at $22.5 \mathrm{~kW}$ and $100 \mathrm{~Pa}$ : (a) temperature, (b) velocity, (c) pressure, (d) Mach number, and (e) Knudsen number.

The Mach number field (Figure 5d) reveals that a Mach disk ends the first expansion zone; it is followed by a small subsonic zone before the jet becomes supersonic again. Figure 5e shows 2D spatial distribution of the gradient-length local Knudsen number (Kn) of $\mathrm{Ar}-\mathrm{H}_{2}$ plasma jet. It can be seen that the $\mathrm{Kn}$ value increases significantly near the exit of the spray torch and before and after the first shock center. According to the definition of $\mathrm{Kn}$, the increase of the $\mathrm{Kn}$ value is not only due to the increase of the mean free path due to the lower pressure, but also the increase of the flow gradient.

If the addition of hydrogen to the argon gas results in an increase in the plasma enthalpy, it also changes the properties of the gas mixture and, in particular, increases its thermal conductivity. The low temperatures found in the near-field region can be explained 
by the energy consumed by the dissociation of the hydrogen molecules and the rather important radial expansion of the flow by its high thermal conductivity. The rather high thermal conductivity and viscosity of the plasma gas compared to low temperature gases act as shock-broadening mechanisms and yield an increase in the shock wave thickness [22]. In addition, the normal shock region is also thickened because of rarefaction effects.

\subsubsection{Ar-He Plasma Jet}

Figure 6a-c show the temperature, velocity and pressure fields of the Ar-He plasma jet in the whole simulation domain, simulated at a net power of $60 \mathrm{~kW}$ and $100 \mathrm{~Pa}$ pressure (high-power plasma torch). Because of the high electric power dissipated in the plasma jet, the plasma jet extends up to $2 \mathrm{~m}$; its maximum velocity reaches about $8000 \mathrm{~m} / \mathrm{s}$; its temperature still reaches about $9000 \mathrm{~K}$ and its velocity $3000 \mathrm{~m} / \mathrm{s}$ at one meter downstream from the torch exit. In the near-field zone (up to $1 \mathrm{~m}$ ), the plasma jet presents large magnitude of fluctuations of temperature, velocity and static pressure. After this zone, the variations of the flow characteristics become small and its pressure homogenizes with the ambient pressure. Helium is characterized by a high viscosity above $12,000 \mathrm{~K}$ $\left(3.67 \times 10^{-4} \cdot \mathrm{kg} \cdot \mathrm{m}^{-1} \cdot \mathrm{s}^{-1}\right)$ compared to argon $\left(2.56 \times 10^{-4} \mathrm{~kg} \cdot \mathrm{m}^{-1} \cdot \mathrm{s}^{-1}\right)$ and hydrogen $\left(7.30 \times 10^{-5} \mathrm{~kg} \cdot \mathrm{m}^{-1} \cdot \mathrm{s}^{-1}\right)$. It reaches a maximum of $4.34 \times 10^{-4} \mathrm{~kg} \mathrm{~m}{ }^{-1} \cdot \mathrm{s}^{-1}$ at $16,000 \mathrm{~K}$ which corresponds to the temperature of the plasma jet issuing in the deposition chamber. This high viscosity delays the mixing of the plasma gas with the ambient gas, the radial expansion of the jet and its mixing as long as its temperature is high enough.

The Mach field (Figure 6d) presents characteristics similar to that of the $\mathrm{Ar}-\mathrm{H}_{2}$ field, but the Mach number is high on a longer distance as the plasma jet velocity is higher and compensates the increase in the sound velocity with the gas temperature (for the $\mathrm{Ar}-\mathrm{He}$ and $\mathrm{Ar}-\mathrm{H}_{2}$ mixtures of this study, the sound velocity is about $3000 \mathrm{~m} / \mathrm{s}$ at 15,000 K [41]). From Figure 6e, it can be seen that 2D spatial distribution of Kn value of Ar-He plasma jet. It clearly shows that the Kn value is less than 0.2 in most parts of the jet field. The plasma jet temperature and velocity decrease in downstream of the normal shock region. The flow gradients are no longer as strong as that in the pre-shock region, and the Kn value decrease in this flow.

\subsection{Effect of the Net Power Input to the Torch and Chamber Pressure \\ 3.2.1. Ar- $\mathrm{H}_{2}$ Plasma Jet}

Figure $7 \mathrm{a}-\mathrm{c}$ show the variation of the temperature, velocity and gradient-length local Knudsen number $(\mathrm{Kn})$ along the plasma torch axis for three different net powers input to the plasma torch $(22.5,30$ and $40 \mathrm{~kW}$ that is an increase by 33 and $78 \%$ of the $22.5 \mathrm{~kW}$ input power) at a chamber pressure of $100 \mathrm{~Pa}$. The first peaks in Figure $6 \mathrm{a}, \mathrm{b}$ correspond to the nozzle exit; it is followed by the plasma jet expansion in the low- pressure chamber. As expected, the increase in the torch power that brings about an increase in the plasma jet enthalpy, results in an increase in the plasma temperature and velocity. It also yields a decrease in the temperature fluctuation resulting from the shock waves as the increase in plasma enthalpy partly compensates the energy consumed by the hydrogen molecules dissociation. 

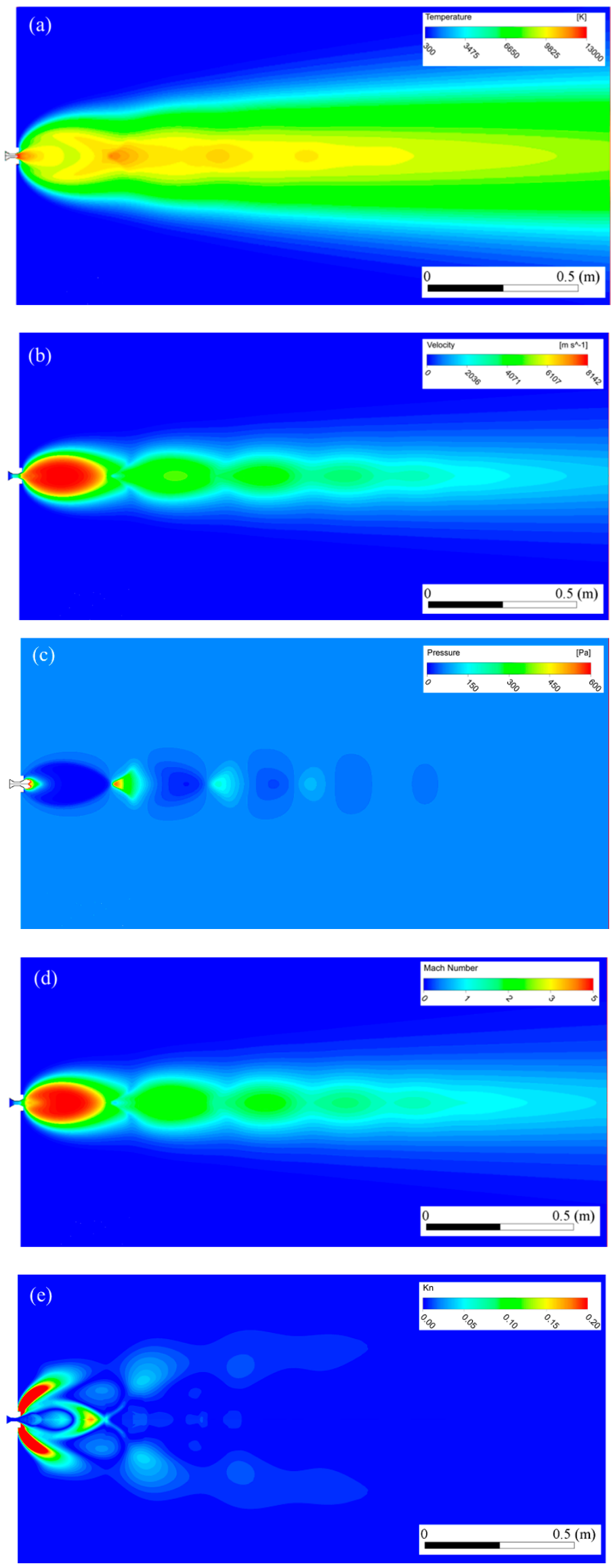

Figure 6. 60Ar-30He plasma jet fields at $60 \mathrm{~kW}$ and $100 \mathrm{~Pa}$ : (a) temperature, (b) velocity, (c) pressure, (d) Mach number, and (e) Knudsen number. 


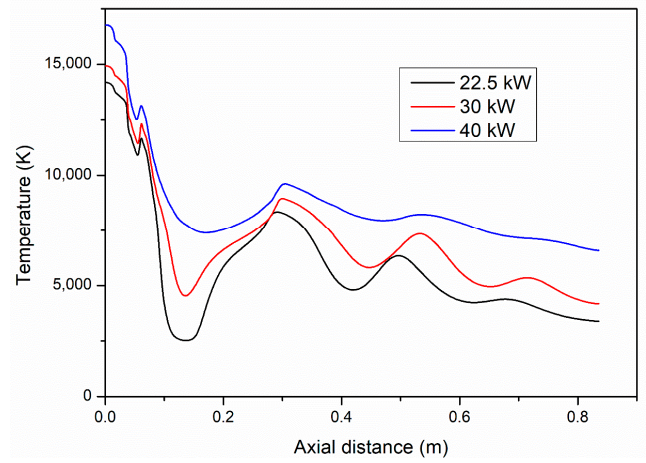

(a)

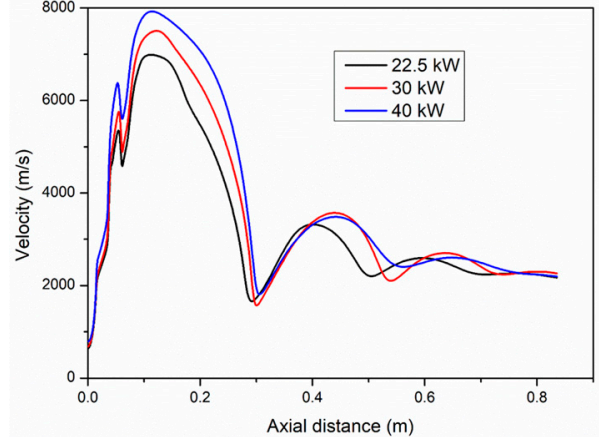

(b)

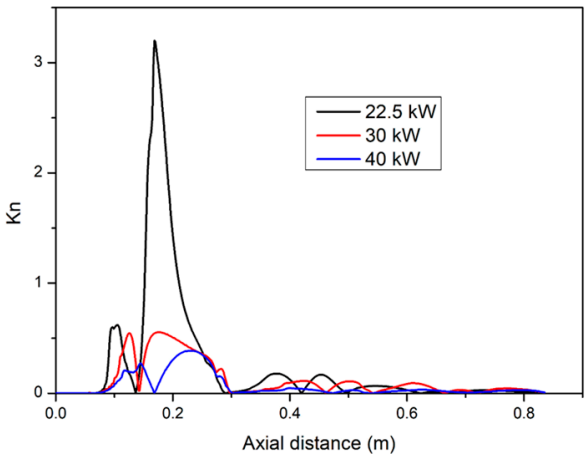

(c)

Figure 7. Variation of the $40 \mathrm{Ar}-8 \mathrm{H}_{2}$ plasma jet (a) temperature, (b) velocity, and (c) Knudsen number along the torch axis for different net powers at $100 \mathrm{~Pa}$.

Moreover, the increase in the arc net power results in a decrease in the peak values of Kn because of the lower local gradients of plasma jet temperature, velocity and density. It can be noticed that when the net power input to the torch is increased up to $40 \mathrm{~kW}$ the peak value of $\mathrm{Kn}$ is less than 0.4 and the values of $\mathrm{Kn}$ are lower than 0.2 from $0.3 \mathrm{~m}$ downstream of the nozzle exit.

Figure $8 \mathrm{a}-\mathrm{c}$ show the effect of the chamber pressure $(100,200$ and $500 \mathrm{~Pa})$ on the variation of the temperature, velocity and Knudsen number of the plasma jet along the plasma torch axis at a net electric power of $40 \mathrm{~kW}$. When the chamber pressure increases, the first shock zone position comes closer to the nozzle exit. The axial fluctuations amplitude of plasma jet temperature and velocity decrease more rapidly and the plasma jet is shortened as the mixing with the ambient gas cools and slows down more efficiently the plasma jet as the barrel shock in rarefied flow does not protect the supersonic gas from mixing with the ambient gas. Mazouffre et al. [42] demonstrated that this effect is especially pronounced for light gases as hydrogen as it diffuses more easily.

It can also be seen in Figure 7c that, except in the region corresponding to the expansion region of the first shock where its value reaches $0.4, \mathrm{Kn}$ is less than 0.05 . The region where the continuum breakdown occurs becomes narrower with the increase of pressure as the flow fields fluctuations decreases. At $100 \mathrm{~Pa}$, it extends from $0.05 \mathrm{~m}$ to $0.3 \mathrm{~m}$ while at $500 \mathrm{~Pa}$, it is limited between 0.05 and $0.18 \mathrm{~m}$ downstream of the nozzle exit.

\subsubsection{Ar-He Plasma Jet}

Figure $9 \mathrm{a}-\mathrm{c}$ show the effect of the net power input to the torch on the temperature, velocity and gradient-length local Knudsen number of the Ar-He plasma jet at $100 \mathrm{~Pa}$ for an electric power of 50,60 and $70 \mathrm{~kW}$. The increase in the net power of the plasma jet (an increase by $20 \%$ and $40 \%$ of the $50 \mathrm{~kW}$ input power) brings about a slight increase in the temperature and velocity of the plasma jet. The increase is less marked than with the $\mathrm{Ar}-\mathrm{H}_{2}$ plasma jet because the power increase is lower and the properties of helium (higher viscosity and higher ionization temperature than hydrogen) tend to lessen the variations. 


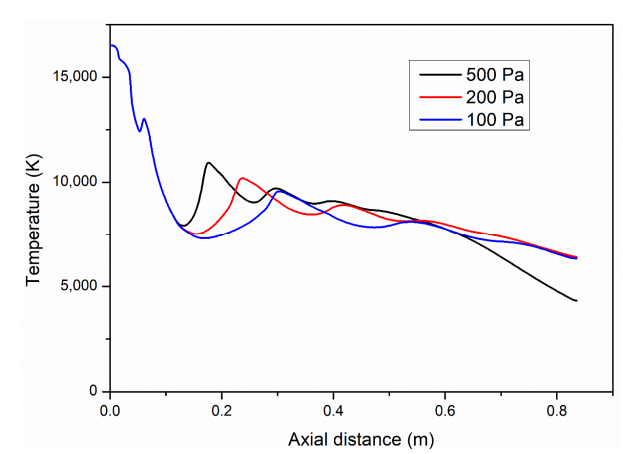

(a)

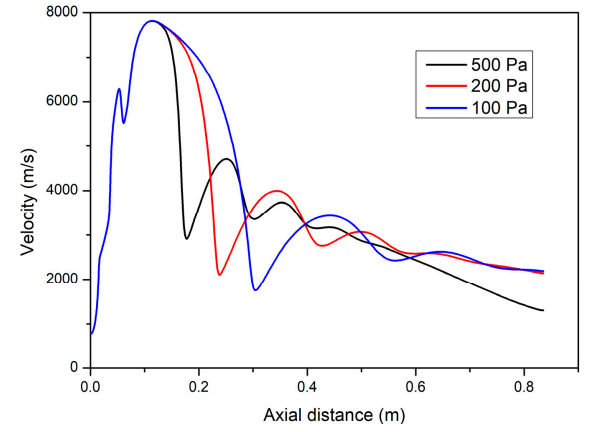

(b)

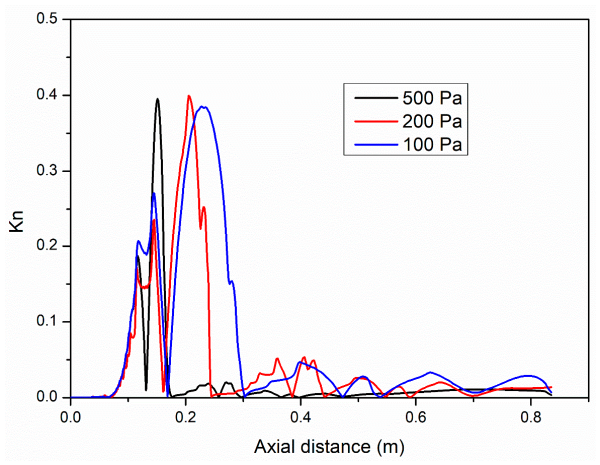

(c)

Figure 8. Variation of the $40 \mathrm{Ar}-8 \mathrm{H}_{2}$ plasma jet (a) temperature, (b) velocity, and (c) Knudsen number along the torch axis distribution for different chamber pressures at a power input of $40 \mathrm{~kW}$.

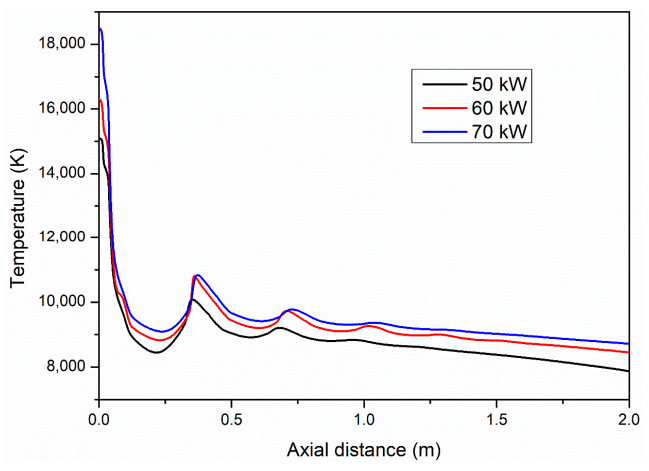

(a)

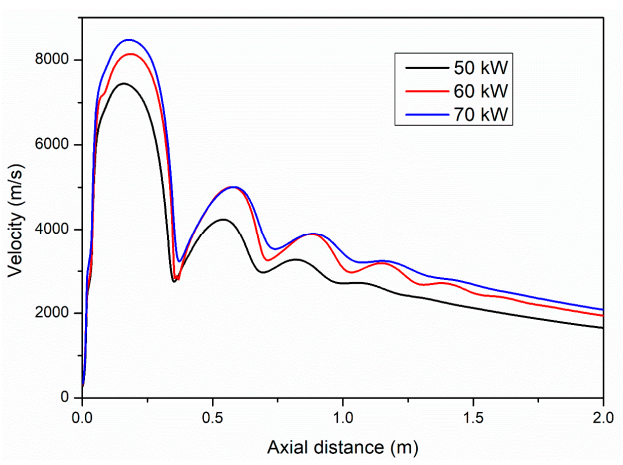

(b)

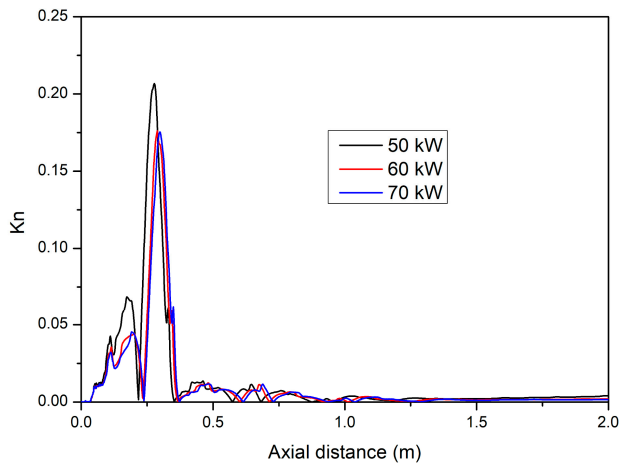

(c)

Figure 9. Variation of the 60Ar-30He plasma jet (a) temperature, (b) velocity, and (c) Knudsen number along the torch axis for different net powers at $100 \mathrm{~Pa}$. 
This also explains the little variation of $\mathrm{Kn}$ along the plasma jet axis with the variation in the plasma torch power input. $\mathrm{Kn}$ is lower than 0.05 except in the first shock that extends from 0.25 to $0.35 \mathrm{~m}$ from the plasma torch exit. Its maximum value is 0.2 .

Figure $10 \mathrm{a}-\mathrm{c}$ show the variation of the temperature, velocity and $\mathrm{Kn}$ of the Ar-He plasma jet along the plasma jet axis at a net power of $60 \mathrm{~kW}$ for a chamber pressure of 100, 200 and $500 \mathrm{~Pa}$. The temperature and velocity variations show the same trends with an increase in the chamber pressure than the $\mathrm{Ar}-\mathrm{H}_{2}$ plasma jet. The shocks get closer to the torch exit and their amplitude and thickness decrease when the pressure increases. The mixing of the plasma jet with the ambient gas is more efficient when the chamber pressure increases and yield a fast decrease in the plasma jet velocity and temperature as it expands in the chamber. It can be seen in Figure $9 \mathrm{c}$ that the Kn peak values are almost the same and below 0.2 for the conditions of this study.

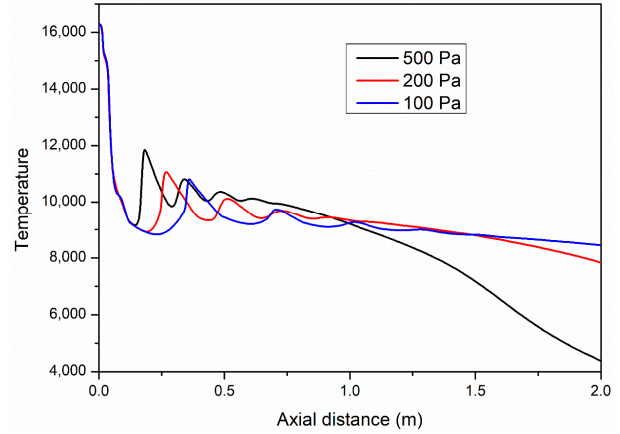

(a)

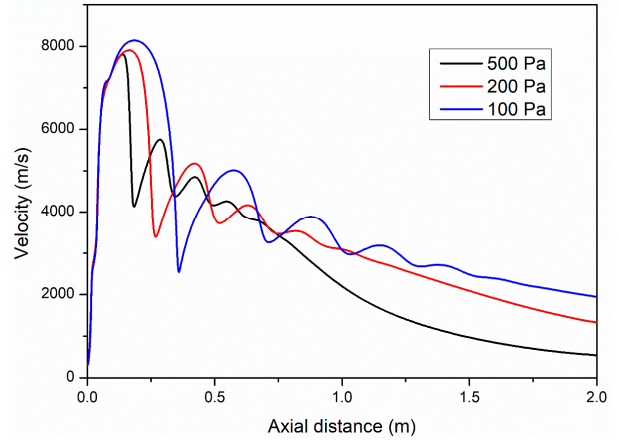

(b)

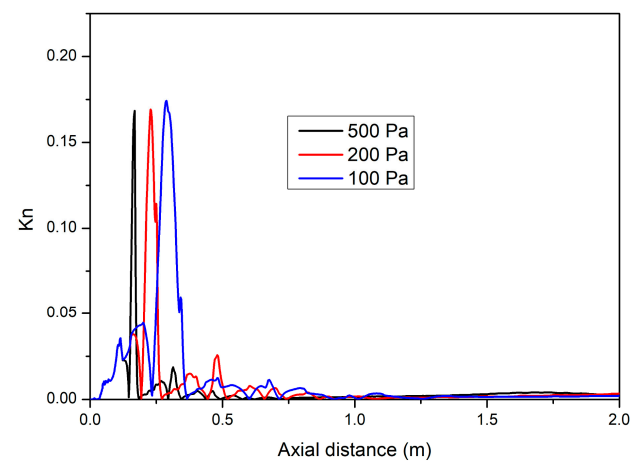

(c)

Figure 10. Variation of the 60Ar-30He plasma jet (a) temperature, (b) velocity, and (c) Knudsen number along the torch axis for different chamber pressures at a power input of $60 \mathrm{~kW}$.

The axial length range on which $\mathrm{Kn}$ is higher than 0.05 is also reduced when the pressure increases. At high electrical power, the effect of the chamber pressure on the $\mathrm{Kn}$ peak value is limited and mainly affects the location of the $\mathrm{Kn}$ peak, which corresponds to the location of the first shock.

\subsection{Effect of the Chamber Pressure and Plasma Arc Power on the Continuum Breakdown}

By comparing the two-dimensional spatial distribution and axial distribution of $\mathrm{Kn}$ value with the change of power and pressure, the local Kn can be introduced for detecting conditions where the continuum approach is valid and in the $2 \mathrm{D} \mathrm{Kn}$ spatial profile of Ar-He, $\mathrm{Kn}$ is less than 0.2, more than 90\%. Under the PS-PVD conditions of this study, the plasma arc power and chamber pressure have some effect on the value of the gradient length local Knudsen number (Kn): an increase in the plasma arc power or in the pressure of the deposition chamber yields a decrease in Kn. Also, an increase of the chamber pressure results in a shortening in the region where Kn exhibits a peak value. When the arc net power is at least equal to $40 \mathrm{~kW}, \mathrm{Kn}$ is lower than 0.2 for both gas mixtures of this study. 
For a lower arc power and pressure of $100 \mathrm{~Pa}$, the region where $\mathrm{Kn}$ is higher than 0.2 is limited to the downstream region of the first shock wave; it decreases when the chamber pressure increases.

Meanwhile, according to Selezneva's investigation [22], for an argon rarefied plasma flow expanding in a low pressure (20-100 Pa) chamber, the results of continuum mechanics satisfactorily agree with the experimental results and the DSMC simulations. In Selezna's study, Kn was lower than 0.15 and the authors concluded that, the models based on the continuum approach can serve the engineering purposes of evaluating the properties of supersonically expanding plasma even if more accurate description of the flow can be obtained with the DSMC simulations. Boyd's study [27] dealing with the simulation of supersonic flow fields at 10 Mach number, also showed that the CFD results were consistent with the DSMC predictions when Kn was lower than 0.2. This condition applies in the whole computational domain when the arc power is higher than $50 \mathrm{~kW}$ even at a chamber pressure of $100 \mathrm{~Pa}$ under the conditions of this study. Generally, in PS-PVD, a high arc power is required to efficiently evaporate the processed powder particles. CFD calculations could be used to capture the shockwave in plasma jet expansion and obtain the reliable temperature, velocity and other characteristics of plasma jet, under such conditions, to help in the optimization of the operating parameters of the process.

\section{Conclusions}

In this work, CFD simulations of plasma jets under PS-PVD conditions were performed in order: (i) to understand the effect of the net electric power input to the plasma torch and deposition chamber pressure on the structure and characteristics of $\mathrm{Ar}-\mathrm{H}_{2}$ and $\mathrm{Ar}-\mathrm{He}$ plasma jet and (ii) evaluate potential continuum breakdowns in the computational domain. The arc power was varied between 22.5 to $40 \mathrm{~kW}$ for the $\mathrm{Ar}-\mathrm{H}_{2}$ plasma jet and between 50 and $70 \mathrm{~kW}$ for the Ar-He plasma jet; the chamber pressure was varied between 100 and $500 \mathrm{~Pa}$. The local gradient Knudsen number was used as the breakdown parameter.

Based on the results, the supersonic plasma jets showed the characteristics of a highly under-expanded jet with the presence of Mach disk and barrel shock. The net arc power increase had a more obvious effect on plasma jet temperature and velocity than the chamber pressure under the conditions of this study. The local gradient Knudsen number (Kn) was significantly affected by the plasma net power. The Kn peak value in this region decreased rapidly with an increase in the net power and the width of this region decreased with an increase in the deposition chamber pressure. After the results of the prior works and this study, it is suitable to calculate the local gradient Knudsen number by the CFD method and local Knudsen number can be introduced for detecting conditions where the continuum approach is valid (the basis of the hybrid CFD/DSMC method). Meanwhile, when the net arc power is higher than $40 \mathrm{~kW}$, the CFD simulations could be used to simulate plasma jet characteristics and can serve the engineering purposes of evaluating the dynamical properties of expanding plasma jet under PS-PVD conditions.

Author Contributions: Conceptualization, T.Z. and A.V.; methodology, T.Z. and A.V.; software, T.Z. and G.M.; writing-original draft preparation, T.Z.; writing-review and editing, A.V., G.M., and C.-J.L.; supervision, C.-J.L.; funding acquisition, C.-J.L. and T.Z. All authors have read and agreed to the published version of the manuscript.

Funding: This research was financially supported by National Basic Research Program (Grant No. 2012CB625104) and joint PhD program of China Scholarship Council. (Grant No. 201506280146).

Institutional Review Board Statement: Not applicable.

Informed Consent Statement: Not applicable.

Data Availability Statement: The data presented in this study are available on request. 
Acknowledgments: The authors would like to thank the support of the China Scholarship Counciland HPC Platform, Xi'an Jiaotong University.

Conflicts of Interest: The authors declare no conflict of interest.

\section{References}

1. Goral, M.; Kotowski, S.; Nowotnik, A.; Pytel, M.; Drajewicz, M.; Sieniawski, J. PS-PVD deposition of thermal barrier coatings. Surf. Coat. Tech. 2013, 237, 51-55. [CrossRef]

2. Mauer, G.; Jarligo, M.O.; Rezanka, S.; Hospach, A.; Vassen, R. Novel opportunities for thermal spray by PS-PVD. Surf. Coat. Tech. 2015, 268, 52-57. [CrossRef]

3. von Niessen, K.; Gindrat, M.; Refke, A. Vapor phase deposition using plasma spray-PVD (TM). J. Therm. Spray Technol. 2010, 19, 502-509. [CrossRef]

4. Smith, M.F.; Hall, A.C.; Fleetwood, J.D.; Meyer, P. Very low pressure plasma spray-a review of an emerging technology in the thermal spray community. Coatings 2011, 1, 117-132. [CrossRef]

5. Wen, J.; Song, C.; Liu, T.; Deng, Z.; Niu, S.; Zhang, Y.; Liu, L.; Liu, M. Fabrication of dense gadolinia-doped ceria coatings via very-low-pressure plasma spray and plasma spray physical vapor deposition process (vol 9, 717, 2019). Coatings 2020, 10, 292. [CrossRef]

6. He, W.T.; Mauer, G.; Schwedt, A.; Guillon, O.; Vassen, R. Advanced crystallographic study of the columnar growth of YZS coatings produced by PS-PVD. J. Eur Ceram. Soc. 2018, 38, 2449-2453. [CrossRef]

7. Anwaar, A.; Wei, L.; Guo, Q.; Zhang, B.; Guo, H. Novel prospects for plasma spray-physical vapor deposition of columnar thermal barrier coatings. J. Therm. Spray Technol. 2017, 26, 1810-1822. [CrossRef]

8. He, W.T.; Mauer, G.; Vaßen, R. Excitation temperature and constituent concentration profiles of the plasma jet under plasma spray-pvd conditions. Plasma Chem. Plasma Process. 2017, 37, 1293-1311. [CrossRef]

9. Shinozawa, A.; Eguchi, K.; Kambara, M.; Yoshida, T. Feather-like structured ysz coatings at fast rates by plasma spray physical vapor deposition. J. Therm. Spray Technol. 2010, 19, 190-197. [CrossRef]

10. Mauer, G. numerical study on particle-gas interaction close to the substrates in thermal spray processes with high-kinetic and low-pressure conditions. J. Therm. Spray Technol. 2019, 28, 27-39. [CrossRef]

11. Chen, Q.-Y.; Li, C.-X.; Zhao, J.-Z.; Yang, G.-J.; Li, C.-J. Microstructure of YSZ coatings deposited by PS-PVD using 45 kW shrouded plasma torch. Mater. Manuf. Process. 2015, 31, 1183-1191. [CrossRef]

12. Zhang, N.; Sun, F.; Zhu, L.; Planche, M.P.; Liao, H.; Dong, C.; Coddet, C. Measurement of specific enthalpy under very low pressure plasma spray condition. J. Therm. Spray Technol. 2012, 21, 489-495. [CrossRef]

13. Gao, Y.; Yang, D.M.; Gao, J.Y. Characteristics of a plasma torch designed for very low pressure plasma spraying. J. Therm. Spray Technol. 2012, 21, 740-744. [CrossRef]

14. Schmitt, M.P.; Harder, B.J.; Wolfe, D.E. Process-structure-property relations for the erosion durability of plasma spray-physical vapor deposition (PS-PVD) thermal barrier coatings. Surf. Coat. Tech. 2016, 297, 11-18. [CrossRef]

15. Mauer, G.; Vaßen, R. Plasma Spray-PVD: Plasma characteristics and impact on coating properties. J. Phys. Conf. Ser. 2012, 406, 012005. [CrossRef]

16. Mao, J.; Liu, M.; Deng, C.G.; Deng, C.M.; Zhou, K.S.; Deng, Z.Q. preparation and distribution analysis of thermal barrier coatings deposited on multiple vanes by plasma spray-physical vapor deposition technology. J. Eng. Mater. Technol. 2017, 139, 041003. [CrossRef]

17. Ivchenko, D.; Mariaux, G.; Vardelle, A.; Goutier, S.; Itina, T.E.; Andre, P. Feasibility study of an adaptive-pressure plasma coating process-part 1: Model description. J. Therm. Spray Technol. 2020, 29, 25-37. [CrossRef]

18. Mauer, G. Plasma characteristics and plasma-feedstock interaction under ps-pvd process conditions. Plasma Chem. Plasma Process. 2014, 34, 1171-1186. [CrossRef]

19. Liu, M.-J.; Zhang, M.; Zhang, Q.; Yang, G.-J.; Li, C.-X.; Li, C.-J. Gaseous material capacity of open plasma jet in plasma spray-physical vapor deposition process. Appl. Surf. Sci. 2018, 428, 877-884. [CrossRef]

20. Ghalandari, M.; Mirzadeh Koohshahi, E.; Mohamadian, F.; Shamshirband, S.; Chau, K.W. Numerical simulation of nanofluid flow inside a root canal. Eng. Appl. Comput. Fluid Mech. 2019, 13, 254-264. [CrossRef]

21. Ivchenko, D.; Zhang, T.; Mariaux, G.; Vardelle, A.; Goutier, S.; Itina, T.E. on the validity of continuum computational fluid dynamics approach under very low-pressure plasma spray conditions. J. Therm. Spray Technol. 2018, 27, 3-13. [CrossRef]

22. Selezneva, S.E.; Boulos, M.I.; van de Sanden, M.C.M.; Engeln, R.; Schram, D.C. Stationary supersonic plasma expansion: Continuum fluid mechanics versus direct simulation monte carlo method. J. Phys. D Appl. Phys. 2002, 35, 1362-1372. [CrossRef]

23. Abbate, G.; Kleijn, C.R.; Thijsse, B.J.; Engeln, R.; van de Sanden, M.C.M.; Schram, D.C. Influence of rarefaction on the flow dynamics of a stationary supersonic hot-gas expansion. Phys. Rev. E 2008, 77, 036703. [CrossRef] [PubMed]

24. Vautherin, B.; Planche, M.P.; Bolot, R.; Quet, A.; Bianchi, L.; Montavon, G. Vapors and droplets mixture deposition of metallic coatings by very low pressure plasma spraying. J. Therm. Spray Technol. 2014, 23, 596-608. [CrossRef]

25. Bird, G.A. breakdown of translational and rotational equilibrium in gaseous expansions. AIAA J. 1970, 8, 1998-2003. [CrossRef]

26. Bird, G.A. Recent advances and current challenges for DSMC. Comput. Math. Appl. 1998, 35, 1-14. [CrossRef]

27. Boyd, I.D. Predicting breakdown of the continuum equations under rarefied flow conditions. AIP Conf. Proc. 2003, 663, 899-906.

28. Wang, W.L.; Boyd, I.D. Predicting continuum breakdown in hypersonic viscous flows. Phys. Fluids 2003, 15, 91-100. [CrossRef] 
29. Wang, W.L.; Sun, Q.H.; Boyd, I.D. Assessment of a hybrid method for hypersonic flows. AIP Conf. Proc. 2003, 663, 923-930.

30. Granados-Ortiz, F.J.; Leon-Prieto, L.; Ortega-Casanova, J. Computational study of the application of al ${ }_{2} \mathrm{O}_{3}$ nanoparticles to forced convection of high-reynolds swirling jets for engineering cooling processes. Eng. Appl. Comput. Fluid Mech. 2020, 15, 1-22. [CrossRef]

31. Ye, X.; An, X.; Zhang, H.; Guo, B. Numerical simulation on flow and evaporation characteristics of desulfurization wastewater in a bypass flue. Eng. Appl. Comput. Fluid Mech. 2020, 14, 411-421. [CrossRef]

32. Murphy, A.B. Thermal plasmas in gas mixtures. J. Phys. D Appl. Phys. 2001, 34, R151-R173. [CrossRef]

33. Murphy, A.B. Transport coefficients of helium and argon-helium plasmas. IEEE Trans. Plasma Sci. 1997, 25, 809-814. [CrossRef]

34. Murphy, A.B. Transport coefficients of hydrogen and argon-hydrogen plasmas. Plasma Chem. Plasma Process. 2000, 20, 279-297. [CrossRef]

35. Gordon, S. Computer program for calculation of complex chemical equilibrium-analysis. NASA Ref. Publ. 1994, $1311,1-64$.

36. Mariaux, G.; Vardelle, A. 3-D time-dependent modelling of the plasma spray process. Part 1: Flow modelling. Int. J. Therm. Sci. 2005, 44, 44-357. [CrossRef]

37. Bird, G.A. definition of mean free-path for real gases. Phys. Fluids 1983, 26, 3222-3223. [CrossRef]

38. Burt, J.M.; Boyd, I.D. A hybrid particle approach for continuum and rarefied flow simulation. J. Comput. Phys. 2009, 228, 460-475. [CrossRef]

39. Buchmann, N.A.; Atkinson, C.; Soria, J. Ultra-high-speed tomographic digital holographic velocimetry in supersonic particleladen jet flows. Meas. Sci. Technol. 2013, 24, 024005. [CrossRef]

40. Han, P.; Chen, X. Modeling of the supersonic argon plasma jet at low gas pressure environment. Thin Solid Film. 2001, 390, 181-185. [CrossRef]

41. Pateyron, B.; Elchinger, M.F.; Delluc, G.; Fauchais, P. Sound velocity in different reacting thermal plasma systems. Plasma Chem. Plasma Process. 1996, 16, 39-57. [CrossRef]

42. Mazouffre, S.; Boogaarts, M.G.H.; Bakker, I.S.J.; Vankan, P.; Engeln, R.; Schram, D.C. Transport of ground-state hydrogen atoms in a plasma expansion. Phys. Rev. E 2001, 64, 016411. [CrossRef] [PubMed] 